\title{
한국 ODA의 시민사회 협력정책과 시민사회 지표의 활용
}

이 남 섭 (한일장신대 NGO 정책대학원 원장)

\section{목 차}

1. 문제의식

2. 선진국 $\mathrm{ODA}$ 의 시민사회 협력관계 동향

3. 한국 $\mathrm{ODA}$ 의 시민사회 협력관계 현황

4. CIVICUS의 시민사회 지표 비교검토

5. 한국과 라틴아메리카의 시민사회 지표 연구사례

6. 문제점과 정책적 제언

\section{1. 문제의식}

지난 2010년 1월 우리나라가 선진공여국 포럼인 개발원조위원회(DAC: Development Assistance Committee)에 가입하면서 ODA 실천전략에 대한 논의가 매우 활발하게 전개되고 있다. 특히 ODA 실천전략이 선진국형 $\mathrm{ODA}$ 모델을 개발하는 것으로 진행되면서 국내외적으로 많은 주목을 받고 있다1).

$\mathrm{DAC}$ 가입이전까지 우리나라의 $\mathrm{ODA}$ 실천전략은 정부중심의 $\mathrm{ODA}$ 전략이었으며 시민사회와

1) 선진국형 ODA모델에 대한 논의는 다음을 참고할 수 있다: 권율 외(2009); 국제개발협력위원회(2010); 이련주 (2010); 서용석(2011). 
의 협력관계는 아주 미비하였다. 즉 우리나라의 ODA는 유상원조와 구속성 원조의 비중이 큰 편이며, 최빈국이나 아프리카 지역보다 저소득국 및 아시아지역에 대한 지원을 우선으로 하는 특징을 지니고 있다. 선진국 회원국들이 거버넌스나 사회분야 그리고 평화구축 문제에 집중하 면서 다양한 부문을 중시하고 있다면 우리나라는 경제와 생산 부분에 많은 지원을 하고 있었다 (서용석, 2011: xvii).

우리나라 ODA가 선진국형으로 발전하기 위해서는 한국형 ODA 모형의 정립, ODA 규모의 제고, 국제사회의 규범과 가치존중, 분절적인 추진체계의 개선, 시민사회 및 민간부문과의 협력 등이 요구되고 있다. 특히 우리나라 ODA 정책의 효과성 제고를 위한 정책제언으로 시민사회의 ODA 참여 및 지원역량의 강화가 우선적으로 제안되었다 (서용석, 2011: xxvii)

선진국형 ODA 모형의 주요 내용은 시민사회 협력전략이다. 1990년대 영국에서 시작된 신정 책의제에 따라 많은 선진공여국들이 $\mathrm{NGO}$ 에 대한 $\mathrm{ODA}$ 의 지원을 본격적으로 추진하기 시작하 였다. 이러한 정책전환은 개별국가 뿐만 아니라 세계은행과 같은 다자간 원조를 지원하는 국제 기구들도 $\mathrm{NGO}$ 를 국제개발협력에서 주요 행위자로 빠르게 인식하고 활용하는 것으로 나타났 다. 선진공여국의 시민사회 지원정책의 주요 흐름은 공여국 개발원조 정책과의 조화와 일치, 시 민사회단체(CSO)의 개발효과성 제고, 국제개발협력에서 비전통적인 시민사회단체(CSO)의 참 여확대를 추구하고 있다 (홍재환, 2011: xiv).

한국 $\mathrm{ODA}$ 의 이러한 정책 변화는 매우 바람직한 현상이다. 그러나 시민사회와의 역량강화와 인증제도의 도입 등을 통한 협력강화를 논의하면서 국제적 차원에서 활발히 진행되고 있는 시 민사회 지표를 시민사회 협력정책에 활용하고 있지 않는 것은 놀라운 일이다. ${ }^{2)}$ 특히 포괄적인 민간단체의 개입을 장려하기 위해 기업의 $\mathrm{CSR}$ 지수는 긍정적으로 논의하는 것과 비교하여 볼 때 매우 대조적인 상황이다. 필자의 경우 지난해 중남미 진출 한국기업의 CSR 실태를 현장조사 하면서 기업의 $\mathrm{CSR}$, 시민사회의 시민사회 지표, 코이카의 $\mathrm{ODA}$ 프로그램이 협력할 필요가 있 음을 제안하였다 (오삼교 외, 2011). 이 글은 이러한 문제의식의 연장선에서 시작되었다. 즉 CIVICUS의 시민사회 지표가 한국ODA의 시민사회협력 정책개발에 적극적으로 활용될 필요가 있다는 문제의식에서 출발한다.

2) 국제개발협력 학술지의 2003년 창간호부터 지금까지 검색한 결과 CSR지표를 다룬 논문은 아직 한건도 없었다. 이와 대조적으로 국제개발협력과 관련하여 기업의 CSR 활용에 대한 논문은 최근에 여러 편 발표되고 있다. 대표 적인 논문으로는 김성규의 논문(2012)을 참고할 수 있다. 
이 글은 먼저 선진국과 우리나라의 시민사회협력관계 동향과 현황을 살펴보고 그 다음 시민사 회 협력관계의 주요 가이드가 되는 CIVICUS의 시민사회 지표를 소개할 것이다. 마지막으로 이 지표가 지닌 문제점과 우리나라 $\mathrm{ODA}$ 의 시민사회협력 전략을 위한 정책적 제언을 제시한다.

\section{2. 선진국 ODA의 시민사회 협력관계 동향}

해외 선진국에서 $\mathrm{ODA}$ 와 시민사회의 협력관계에 대한 논의와 연구는 매우 활발하다. 이것은 이러한 연구의 결과가 바로 국제적 기준과 규범으로 발전되어 나타난다는 점에서 확인된다. $\mathrm{OECD} \mathrm{DAC}$ 에 따르면 $\mathrm{ODA}$ 는 개발 $\mathrm{NGO}$ 에 공여되어야 한다는 것을 명확히 하고 있다. 또 개 발원조에서는 공여국 정부나 국제기구의 역할이 강조되는 반면에, 국제개발협력에서는 3차 원 조효과성 제고를 위한 아크라회의의 결과인 아크라행동선언이 강조하듯이 시민사회 및 기업 등 민간의 참여가 강조되고 있다. 결국 국제개발협력은 개발도상국의 경제사회적 발전을 위해 정 부나 국제기구 및 시민사회, 기업 등 다양한 공여주체들과 수원국이 함께 참여하는 개념이다 (홍재환, 2011: 14). 최근 $\mathrm{OECD}$, 유엔기구, 세계은행 등 국제개발협력의 다양한 주체들이 기존 에 국제개발협력 사업을 수행해온 개발 $\mathrm{NGO}$ 보다 좀 포괄적인 개념을 가진 $\mathrm{CSO}$ Civil Society Organization, 시민사회단체)라는 용어를 활용하는 것은 진일보한 현상이다.

1980년대 이후 국제개발협력에 시민사회가 적극적으로 참여하게 된 배경에는 크게 여섯 가지 의 주요 요인이 있다. 첫째 정부의 실패로 인한 민영화와 정부기능의 축소, 둘째 민주주의의 확 장, 셋째 $\mathrm{NGO}$ 에 대한 공공분야의 지원증대, 넷째 무정부주의 상태의 증대, 다섯째 냉전의 종식 으로 인한 독립 및 내전증대, 마지막으로 국제개발협력에 참여하는 시민사회구성원들의 기부증 대이다 (홍재환, 2011: 20).

1990년대에 추진된 신정책 아젠다는 시민사회에 대한 정부의 재정지원을 강화하였다. 이시기 에 많은 북반구의 개발 $\mathrm{NGO}$ 들은 개발도상국에서 직접 원조 사업을 운영하는 방식으로부터 남 반구 $\mathrm{NGO}$ 들을 대상으로 직접 자금지원과 조직 지원을 하는 방식으로 전환하였다. 많은 북반구 개발 $\mathrm{NGO}$ 가 공여자가 되었고, 남반구 $\mathrm{NGO}$ 들과의 관계에 대해 재정의를 내렸다. 이때부터 파 트너십, 역량강화 등의 개념들이 사용되기 시작하였다 (홍재환 2011: 34).

개발 $\mathrm{NGO}$ 들을 중심으로 하는 시민사회의 다양한 활동주체들은 2000 년대 이후 본격적으로 
다양한 국제회의에 참여하여 개발원조 관련 정책에 영향을 주기 시작하였다. 시민사회는 1992 년에는 리우데자네이루 유엔환경개발회의, 1995년에는 코펜하겐 사회개발정상회의와 북경여성 대회를 시작으로, 2000 년에는 요하네스버그 지속가능발전 사회개발정상회의 등 각종 국제개발 관련 국제회의에 적극적으로 참여하였다. 비록 2001년 9.11 사건이후 테러와의 전쟁을 우선순 위에 둔 국가들이 시민사회협력 정책에 대해 비판적인 입장을 갖게 되었지만 시민사회는 2000 년대 국제개발협력 현장에서 핵심적인 활동주체로 주목받고 있다. 2000년대 중반 이후 국제사 회에서 발간된 주요 연구서 및 정책보고서는 일관되게 원조효과성 이슈와 시민사회 정책과의 연관성에 대해 강조하고 있다. 이는 곧 시민사회에 대한 지원이 국가의 개발원조정책의 큰 그림 속에서 이루어져야 함을 강조하는 것이다 (홍재환, 2011:56).

선진공여국들은 1990 년대부터 원조정책 수행에 있어 시민사회를 적극적으로 받아들여 활용 하였다. 그러나 근래에는 많은 선진공여국들이 국제개발협력에 참여하는 시민사회의 범주에 개 발 $\mathrm{NGO}$ 를 포함하여 더 포괄적인 단체들에게 까지 확장하여 활용하고 있다. 즉 국가와 시장을 제외한 노동조합, 종교기반단체, 각종협회 등을 포함하며, 시민사회내의 비영리를 추구하는 각 종 결사체까지도 포함한다.

이와 같이 개발 $\mathrm{NGO}$ 를 포함한 다양한 시민사회에 대한 선진공여국 정부의 관심은 1990 년대 의 신정책 의제와 깊은 관련이 있다. 선진공여국은 이러한 거버넌스 문제를 해결하기 위한 한 방편으로, 자국의 개발 $\mathrm{NGO}$ 에게 재정지원을 하여 이를 통해 이들의 파트너인 개발도상국의 시 민사회가 성장하여 개발도상국 정부의 책무성을 제고하고, 나아가 굿 거버넌스를 실현하게 하 도록 하는 정책을 전개한 것이다. 이러한 과정에서 공여국은 사회적 서비스 제공을 주로 하는 개발 $\mathrm{NGO}$ 외에도 다양한 주제와 분야에서 활동하는 여성, 인권, 종교, 노조 및 각종 전문단체들 의 참여를 장려하게 되었다 (홍재환, 2011: 64-65). 예를 들면 영국의 정부원조기구인 DFID는 2006년에 발간한 거번넌스에 대한 세 번째 백서에서 개발 NGO 외의 새로운 주체가 개발협력 에 참여해야 할 필요성에 대해 설명하고 있다. 특히 개발협력에 있어서의 비전통적 시민사회와 의 연관성을 가질 필요가 있음을 강조한다 (홍재환, 2011: 65).3)

또 스웨덴은 전통적으로 다양한 시민사회그룹이 국제개발협력에 참여하고 있으며 이 과정에

3) 지난해 개최된 부산세계개발원조총회는 기존의 정부와 정부간 기구대표이외에 시민사회단체를 기업, 의회, 지방정 부 및 지역기구와 함께 국제개발협력의 정식참가자로 총회결과문서 서두에 명시하였다. 이것은 국제개발협력이 더 이상 정부만이 아니라 다양한 행위자의 공동과제라는 인식의 전환을 가져왔음을 의미한다(이성훈 2012: 91). 
서 정부의 제도화된 지원을 받는 국가이다. 2010년에 발간된 원조백서는 개발도상국의 민주화 와 인권증진이 스웨덴 시민사회 지원전략의 목표임을 밝히고 있다. 스웨덴정부는 시민사회 지 원정책의 목표달성을 위한 15 개의 기본 조직 가운데서 $86 \%$ 인 13 개에 해당하는 국제개발협력에 서의 비전통적인 시민사회단체(CSO)를 지원하고 있다. 최근에는 공여국들의 협력대상이 기존 의 시민사회에서 더욱 확대되어 전통적 기업, 사회적 기업 및 기업이 설립한 재단과 민간영역으 로 확대되고 있는 추세이다 (홍재환, 2011: 67).

\section{3. 한국 ODA의 시민사회 협력관계 현황}

최근 국내에서도 지난해 11월말에 개최된 부산세계개발원조총회를 전후로 하여 ODA에 있어 서 시민사회와의 협력관계에 대한 연구가 활발히 진행되고 있는 것은 매우 고무적인 일이다. 무 엇보다 다행인 것은 ODA와 시민사회의 협력관계 개선에 대한 연구를 민간(이성훈, 2012)뿐만 아니라 정부차원에서도 연구를 심화하고 있다(권율 외, 2009; 이련주, 2010; 김은미 외, 2010; 서용석, 2011; 홍재환, 2011)는 점이다.

우리나라의 $\mathrm{ODA}$ 를 담당하는 기관 중 시민사회를 지원하는 프로그램을 운영하는 대표적인 기 관은 외교통상부 산하의 $\mathrm{KOICA}$ 이다. $\mathrm{KOICA}$ 는 1995 년부터 현재까지 17 년간 민간단체 지원사 업을 통해 한국의 시민사회와 협력하고 있다 (한국국제협력단, 2011).4) 한국정부는 2010년 $\mathrm{OECD} \mathrm{DAC}$ 가입을 전후로 $\mathrm{ODA}$ 규모를 크게 증대하고 있으며 시민사회와의 협력의 중요성을 강조하고 있다. 향후 2015년까지 우리나라는 ODA 액수를 GNI 대비 $0.25 \%$ 로 증대시킬 계획 을 갖고 있다 (국제개발협력위원회, 2010; 이련주, 2010: 131). NGO에 대한 예산을 2015년까 지 2010년의 10배 수준인 900억 규모로 확대한다고 밝혔다 (홍재환, 2011: 182).

이러한 노력에도 불구하고 현재 한국 $\mathrm{ODA}$ 의 시민사회 지원은 선진공여국과 비교해보면 그 규모와 체계면에서 매우 부족한 상태이다. 2011년 OECD 시민사회 보고서는 한국은 단 하나만 의 시민사회 재정지원 프로그램을 운영한다고 밝히고 있다 (홍재환, 2011: 141). 2011년 OECD

4) $\mathrm{KOICA}$ 이외의 기관 중 ODA를 통해 시민사회를 지원하는 기관은 행정안전부, 보건복지부, 교육과학기술부 등이 있다. 
시민사회 보고서에 의하면 한국 ODA의 시민사회 지원은 2009년 US\$11백만으로 OECD DAC 24 개 회원국 중 22 위로 포르투갈과 그리스만이 한국보다 적은 규모이다. 또한 한국의 양자간 원조 대비 시민사회지원 비율은 $2 \%$ 로 프랑스, 그리스, 일본과 함께 최하위를 차지하고 있다. 그 리고 시민사회에 대한 재정지원방식에 있어 한국은 그리스와 더불어 가장 적은 1 가지 방식만을 활용하고 있다. 이는 우리보다도 시민사회 지원 규모가 작은 포르투갈이 6 가지의 다양한 시민 사회 지원방식을 가지고 있는 것과 비교하면 매우 부족한 것이다 (홍재환, 2011: 180-181).

현재 KOICA의 민간단체 지원사업은 지속적으로 사업비 지원 규모의 확대, 단체자 부담비율 의 감소 및 행정비 지원 등 여러 측면에서 개선되고 있다. 그러나 사업의 다양성 측면에서 더욱 개선될 필요가 있다 (홍재환, 2011: 143).

과거 17 년간 $\mathrm{KOICA}$ 의 민간단체지원 사업에 참여하는 개발 $\mathrm{NGO}$ 중심의 시민사회 단체들의 사업분야는 교육, 보건 등 $\mathrm{BHN}$ 분야가 $75.1 \%$ 를 차지한다. 그리고 개발 $\mathrm{NGO}$ 들은 이러한 사업 들을 거의 사회적 서비스 제공방식으로 실행한다. 이러한 특성은 개발도상국 주민들의 즉각적 인 필요를 채우는 데에는 도움이 되지만 더욱 근본적인 접근방식이 필요하다. 다양한 시민사회 단체가 개발도상국의 발전에 기여할 수 있도록 하기 위해서는 시민사회를 지원하는 정부의 인 식 변화외에 실질적인 제도적 변화가 필요하다 (홍재환, 2011: 173).

선진국의 동향과 한국의 현황을 비교해 볼 때 시민사회를 통한 $\mathrm{ODA}$ 지원정책이 매우 필요함 을 확인하게 된다. 이것이 CIVICUS의 시민사회 지표의 적극적 활용을 제기하게 된 배경이다. 이제 CIVICUS의 시민사회 지표를 소개 및 검토한다.

\section{CIVICUS의 시민사회 지표 비교검토}

시민사회 지표(CSI)란 시민사회의 역량을 경험적으로 측정하고 평가하는 기준이다. 현재까지 개발된 시민사회를 측정하는 대표적인 지표로는 다음의 두 가지가 있다. 첫 번째는 1990년에 존스 홉킨스대학의 연구진이 개발한 국제비영리섹터분류법(ICNPO)이고 두 번째는 CIVICUS 가 개발한 시민사회 지표이다 (아래〈표1〉참고). 
〈표 1〉ICNPO와 CIVICUS의 시민사회 지표 비교

\begin{tabular}{c|c|c}
\hline 구분 & ICNPO & CIVICUS \\
\hline 개발연도 & 1990년 & 1997년 \\
\hline 개발기관 및 연구자 & $\begin{array}{c}\text { 존슨홉킨스대학의 샐러먼 } \\
\text { (Salamon)과 안아이어 }\end{array}$ & 안아이어(Anheier) \\
\hline 핵심개념 & 시민사회조직 & 시민사회 \\
\hline 개념정의 & $\begin{array}{c}\text { 공식적, 사적, 비영리적, 자치적, } \\
\text { 자원적 특성을 가진 } \\
\text { 시민사회의조직 }\end{array}$ & $\begin{array}{c}\text { 가족, 국가, 시장의 바깥에서 } \\
\text { 사람들이 공동의 이익을 } \\
\text { 추구하기 위해 조직한 영역 }\end{array}$ \\
\hline 분류영역 & 12개 영역 & 20개 영역 \\
\hline 평가지표 & $\begin{array}{c}\text { 역량(32/45), 지속가능성(38/39) } \\
\text { 영향(36/36), 평균 35(40)점 }\end{array}$ & $\begin{array}{c}\text { 구조(50), 환경(53), 가치(63), } \\
\text { 영향(77), 평균(61점) }\end{array}$ \\
\hline
\end{tabular}

(* 출처: 주성수 편, 2006의 pp.15-41에서 재편집)

$\mathrm{ICNPO}$ 는 시민사회 지표에 대한 계량적 접근법으로 존스홉킨스 대학의 연구진인 샐러먼 (Salamon)과 안아이어(Anheier)가 1990년 대학의 프로젝트로 시작하였다. 그들은 각국 시민 사회의 특성을 전체 경제와 고용, 수입, 지출, 자원봉사 인구 등의 경제적 규모를 통계적으로 측 정하여 국가간 비교를 하였다. 이때 참여한 국가는 미국, 영국, 프랑스, 독일, 스웨덴, 일본, 인 도 등 13개국이었다 (Salamon and Anheier 1997; 주성수 2006: 14-15). 이어서 1999년에는 연구대상 국가를 22 개국으로, 2004년에는 36개국으로 확대하였다. 한국은 2004년의 국제비 교연구에 참여하였다.

$\mathrm{ICNPO}$ 접근법은 시민사회 전체를 체계적으로 분류해서 각 영역의 경제적 규모부터 구성원 의 인력 등 경험적 자료를 중심으로 계량화를 시도한다. 이 접근법은 시민사회 부문의 경험적 데이터베이스를 구축해서 국가간 비교를 가능하게 한 최초의 시민사회 국제비교 분석법으로써 시민사회의 복잡한 측면을 쉽게 이해할 수 있는 분석틀을 제공한다는 장점이 있다. 그러나 양적 측정이 가능한 시민사회 외부의 경험적 실체만을 부각하고 시민사회 내부의 질적인 측면을 경 시한다는 단점이 있다. 이러한 분석방법은 경험적 자료와 통계를 구비한 선진국에는 비교적 용 이하게 조사와 분석을 진행할 수 있지만 이러한 계량적 자료가 부족한 제3세계에는 적용이 어 렵거나 분석에서 불리할 수 있다 (주성수, 2006: 16-17). 
CIVICUS는 ICNPO 연구를 주도한 안아이어 교수가 새로운 시민사회 지표 아이디어를 시민 사회 다이아몬드로 제시하고, CIVICUS가 이를 적극 수용해 2000년부터 14개국에서 시범적으 로 시민사회 지표 분석을 진행하였다. CIVICUS는 시민참여를 위한 세계적 연합운동단체 (World Alliance for Citizen Participation)를 대표하는 용어이다. CIVICUS는 지구상의 모 든 영역에서 시민의 참여를 확산하려는 노력에서 발생하였다. CIVICUS는 처음에 전 세계 6 개 국의 대표 20 명으로 구성되었다. 그 후 1993 년 중반에 기본 6 개국에서 18 개국으로 확대되었다. 2011년에는 6개 대륙의 59개국으로 확대되었다 (www.civicus.org).

시민사회를 측정하는 방법이 다른 것은 시민사회 개념정의와 분류방식 그리고 분석방법의 차 이에서 기인한다. 먼저 개념정의의 차이를 살펴보자. ICNPO가 시민사회 조직에 초점을 맞춘다 면 CIVICUS는 시민사회 영역을 핵심개념으로 파악한다. 전자가 조직의 구조 기능적이고 양적 측면을 중시한다면, 후자는 조직뿐만 아니라 조직에 참여하는 개인의 역동적인 활동과 역할에 초점을 맞춘다 (주성수, 2006:17).

개념의 차이는 자연적으로 분류방식의 차이로 나타난다. ICNPO는 12 개의 분류법을 사용한 다면 CIVICUS는 20개의 분류법을 사용한다. 어떤 분류 항목은 ICNPO의 목록에는 있으나 어 떤 분류 항목은 CIVICUS의 목록에는 없다. 이러한 차이는 개별국가 사례에 적용할 때도 나타 난다. 가령 CIVICUS의 목록에 있는 “인종적 전통적 토착민” 조직은 한국의 현실에 적용하기 어려운 분류방식이다 (주성수, 2006:21).

시민사회 측정의 가장 어려운 점은 측정의 방법에 있다. ICNPO는 경제적 규모(고용, 수입, 지출)를 통계적으로 측정하여 국가간 비교를 하는 양적 방법을 사용하였다. 이와 달리 CIVICUS는 기존의 양적 접근법에 질적 접근법을 혼합한 모델을 개발하였다. CIVICUS는 1단 계에서는 시민사회를 4개의 영역(구조, 환경, 가치, 영향)으로 구분한 다음 이를 종합적으로 평 가하였다. 2 단계에서는 5 개의 영역으로(시민참여, 조직, 가치, 영향력, 외부환경) 심화 구분하 여 분석 평가하였다. 또 조사 진행방법으로는 국내의 문헌 및 자료의 분석, 지역사회의 시민사 회 이해 관계자들을 대상으로 하는 토론과 설문조사, 지역 주민들에 대한 설문조사, 언론에 보 도된 시민사회의 이미지 분석 그리고 이러한 자료들을 근거로 하여 전문가들이 최종적인 평가 점수를 산출하는 과정을 거쳤다 (주성수, 2006).

양적분석과 질적 분석을 병행해야 하는 필요성은 $\mathrm{ICNPO}$ 가 지닌 다음과 같은 문제발생에서 기인한다. 시민사회를 질적 분석 기준으로만 분석할 때 환경 분야 시민운동이 권익주창 활동을 
한 것은 사실이나 ICNPO의 양적분석 기준에서 제외되는 문제가 발생한다. 대부분의 시민사회 활동은 서비스와 권익주창으로 나누어지며 질적인 자료 분석에 의하면 권익주창과 사회운동이 지배적이다. 그러나 양적 자료를 통할 경우 대부분의 시민사회는 서비스 활동이 권익주창 활동 보다 더 지배적이라는 해석이 나올 수 있다 (주성수, 2006: 22).

이러한 방법에 의해 CIVICUS는 전 세계 국가를 대상으로 3단계에 걸쳐 분석을 해왔다. 1단 계는 파일롯(pilot) 단계로 1992-1995년에 6개국을 대상으로 실시하였다. 이를 기반으로 2단 계가 2000-2005년에 18개국을 대상으로 실시하였다. 마지막으로 3단계는 2006-2008년에 30 개국을 대상으로 실시하였다. 한국의 경우는 2 단계에서부터 참여하였다.

요약하면 CIVICUS의 시민사회측정지표는 시민사회의 건강성과 역량을 종합적으로 이해할 수 있는 기준이라고 할 수 있다. 따라서 CIVICUS의 시민사회 지표를 활용한다면 ODA 파트너 인 상대국의 시민사회를 평가하는데 매우 유용할 것이다.

\section{5. 한국과 라틴아메리카의 시민사회 지표 연구사례}

세계시민사회 지표에 대한 국내 연구로는 2002년 성공회대학교의 아시아 NGO 정보센터의 연구팀과 2003년 한양대학교의 제3섹터연구소 연구팀의 연구가 있다. 이 두 대학의 연구는 한 국연구재단의 중점연구소 사업으로 진행되었다. 이 두 연구팀의 공통점은 CIVICUS의 CSI 접 근법을 한국과 아시아의 시민사회를 분석하는 데 적용하였다는 점이다. 그러나 아프리카와 중 남미의 사례가 분석의 대상에서 제외된 것은 이 두 연구팀이 지닌 언어학적 한계의 결과이다.5)

성공회대학교의 연구팀은 한국과 아시아 5 개국 시민사회를 비교 분석하였다. 아시아의 분석 사례로는 일본, 중국, 동남아, 대만, 태국으로 제한하였다 (권혁태 외, 2003; 이남주 외, 2005). 성공회대의 연구는 국내 대학으로는 최초로 국제적으로 발전해 온 시민사회 연구의 조사방법론 을 한국과 아시아 시민사회 연구에 적용했다는 데에 의의가 있다.

5) 이 두 연구팀에 참여하는 공동연구원들은 외국어 사용의 경우 대부분 영어권에 해당한다. 따라서 아프리카와 라틴 아메리카의 시민사회를 연구할 경우 지역연구에 필수적인 어학능력을 지닌 연구진으로 구성하는 것이 절대적으로 요청된다. 
한양대학교의 연구팀은 해외사례보다는 한국 시민사회의 경험적 분석에 초점을 두었다. 즉 한 국시민사회를 좀 더 집중적으로 분석하였다 (주성수, 2006). 이 점에서 성공회대의 연구를 진일 보 시켰다는 평가를 받고 있다. 그러나 한국시민사회의 분석 표본수가 너무 작아 일반화하기에 는 어려운 점이 있다.

최근에 한일장신대학교가 한국연구재단이 지원하는 SSK 사업선정을 계기로 한국형 CSI 측 정모형을 개발하는 연구를 시작하였다. 분석의 범위도 국내의 경우 전국의 시민사회를 대상으 로 보다 많은 표본을 설정하고, 국외의 경우도 아프리카와 중남미 및 전 세계를 분석의 범위에 포함하는 광범위한 연구를 진행하고 있다. 한일장신대의 경우는 10 년 장기 연구과제로써 연구 가 종결되었을 때 세계시민사회의 역량을 평가하고 이해하는데 기여하리라 기대된다.

이들 세 대학이 진행하였고 진행중인 비교론적 연구방법은 한국의 시민사회를 객관화하여 평 가할 수 있는 인식의 기준을 제공한다는 점에서 매우 긍정적이다. 그러나 연구 초기단계에서 우 려했던 것처럼 단순히 시민사회 지표로 각국 시민사회의 전모를 통계적으로 유의미하게 파악하 는 것은 거의 불가능하였다. 특히 평가점수의 절대치 비교보다는 형태비교가 강조되어야 한다 는 점이 공통적으로 지적되었다 (이남주, 2005: 14; 주성수, 2006: 77)

국외 사례로는 라틴아메리카 사례가 주목된다. 그럼 왜 라틴아메리카인가? 우리나라의 해외 원조비 구성을 지역별로 살펴보면 아시아가 약 $18 \%$, 아프리카가 약 $12 \%$, 중남미가 약 $8 \%$ 순이 다 (이련주, 2010: 128).6) 우리나라 전체 원조규모에 견주어 볼 때 라틴아메리카 지역은 중요한 지역은 아니다. 그럼에도 불구하고 라틴아메리카를 선택한 이유는 유럽선진 공여국의 대 라틴 아메리카 시민사회 협력정책이 타 지역에 비해 성공적으로 진행되었다고 평가되기 때문이다. 특히 라틴아메리카의 시민사회가 민주주의 회복, 인권옹호, 인간과 사회개발 기본지수의 향상, 환경보호와 같은 가치의 향상을 위한 지역시민사회의 역량강화에 기여하였음을 CIVICUS의 시 민사회 지표는 보여주고 있다 (CIVICUS, 2011).

CIVICUS의 라틴아메리카 시민사회 측정은 2000년을 기점으로 시작하였다. 그 후 2002년과 2008년 그리고 2011년 세 단계에 걸쳐 진행되었다. 1단계에는 6개국을 조사하였고, 2단계에서 는 8개국을 조사하였다. 1단계 조사에 참여한 국가는 니카라과, 우루과이, 칠레, 멕시코, 아르헨

6) 우리나라의 대라틴아메리카 개발원조정책에 대한 대표적인 논의는 최원식(2005)과 정상희(2011)의 연구를 참고할 수 있다. 
티나, 베네수엘라이다. 2단계 조사에는 아르헨티나, 칠레, 도미니카 공화국, 과테말라, 멕시코, 니카라과, 우루과이, 베네수엘라가 참여하였다. 조사과정은 조사모델에 따라 진행하였다. 1단계 에서는 4 개의 영역(구조, 환경, 가치, 영향)으로 나누어 분석하였고 2 단계에서는 5 개의 영역(시 민참여, 조직, 가치, 영향력, 외부환경)으로 나누어 분석하였다. 2단계 연속으로 참여한 국가는 브라질, 아르헨티나, 우루과이, 칠레 4개국이다 (CIVICUS, 2007; 2010; 2011). 지난 20082011년 기간 동안에 CIVUICUS가 진행한 라틴아메리카 시민사회 지표(CSI) 분석의 대륙별 비 교분석의 주요 내용을 요약하면 다음과 같다.

CIVICUS의 시민사회 지표연구 결과를 비교한 결과 라틴아메리카의 시민사회는 다른 대륙과 비교하여 조직 및 환경부문이 매우 취약하고 시민참여와 가치영역이 강한 특성을 보이고 있으 며 전반적으로 건강한 특성을 지니고 있다. 이것은 한국의 시민사회 특징과 비슷한 모습을 보여 준다.

\section{6. 문제점과 정책적 제언}

시민사회의 역량을 평가하는 과정에 있어서 CIVICUS의 CSI가 많은 기여를 하였음에도 불구 하고 몇 가지 문제가 발견된다. CIVICUS가 시민사회를 측정하는 데 있어서 지적되는 문제는 다음 네 가지이다.

첫 번째 문제는 시민사회 개념정의의 문제이다. 시민사회의 정의는 시민사회를 이해하는 이론 적 관점에 따라 다양하게 정의된다. 대표적인 이론적 관점으로는 서비스제공형 사회자본이론, 권익주창형 사회운동이론, 신사회운동이론이 있다. 즉 이 세 가지 이론적 입장에 따라 시민사회 에 대한 정의는 다르게 나타나며 단 하나의 개념정의가 존재하지 않는다. 따라서 시민사회 개념 정의의 문제가 단순하지 않고 어렵다.

두 번째 문제는 시민사회 특성의 규명문제이다. 라틴아메리카 시민사회의 특성도 서비스, 사 회자본, 권익주창으로 나누어지나 다수의 시민사회단체는 권익주창형이 강하다. 라틴아메리카 시민사회는 한국의 사례와 마찬가지로 서비스와 권익주창형이 이원화되어 상호간의 교류와 관 계없이 각기 별도의 역할을 하고 있는 상황에 있다. 
세 번째 문제는 시민사회 지표를 조사하는 기관의 대표성 문제이다. 조사에 참여하는 대부분 의 기관은 각 나라의 지역사회에서 인정을 받는 $\mathrm{NGO}$ 기관들이다. 라틴아메리카의 사례에서 보 듯이 대표 기관의 성격은 복지사업 관련 서비스를 제공하는 기관이 대부분이고 권익추구형 $\mathrm{NGO}$ 기관은 매우 소수이다. 따라서 이러한 대표성의 한계로 시민사회 지표조사에 있어서 다양 성과 객관성이 문제로 지적된다. 즉 시민사회 지표 분석 대상기관이 대부분 복지서비스 중심단 체로 제한되어 있다는 문제가 있다. 국가별 대표기관의 선정에 있어서 다양성을 확보하는 것이 필요하다.

네 번째 문제는 지표기준이 너무 선진국의 기준을 반영하고 있지 않은가 하는 문제이다. 즉 지표기준의 적합성 문제가 지적된다. 제3세계 시민사회의 특성을 반영하는 기준의 모색이 필요 하다. 선진국과 개발도상국의 지역별 특성을 반영하는 글로벌 기준의 개발이 요청된다.

지금까지 필자는 CIVICUS의 시민사회 지표가 지닌 문제점을 검토하였다. 우리나라 ODA가 성공적으로 추진되기 위해서는 국제개발협력의 광범위한 기반의 확대가 필요하다. 특히 정부와 민간부분이 $\mathrm{ODA}$ 를 공동으로 추진할 수 있는 여건이 준비되어야 한다. 정부와 민간부문이 함께 하는 개발협력 체제를 구축하기 위해서는 먼저 $\mathrm{NGO}$ 와의 협력을 강화할 필요가 있다. 이러한 의미에서 선진국의 시민사회 협력관계를 살펴볼 때 한국 $\mathrm{ODA}$ 의 시민사회 협력관계는 다음과 같은 방향으로 개선할 필요가 있다.

첫째, 시민사회와의 협력관계를 안내하는 기초자료로 CIVICUS의 지표를 활용한다. CIVICUS의 시민사회 지표는 ODA의 시민사회 협력관계를 발전시키는 데 매우 유익한 기준이 된다. CIVICUS의 시민사회 지표는 ODA 수원국 시민사회의 역량을 객관적으로 평가하고 이해 하는 데 도움이 될 것이다. 왜냐하면 한국개발 $\mathrm{NGO}$ 의 경험부족과 역량의 미성숙 및 인력부족 등의 현실도 고려해야 하기 때문이다.

둘째, 장기적으로는 한국사회가 CIVICUS와는 독립된 그러나 보편적인 기준을 충족하는 전 세계 시민사회 평가지표를 개발하고 이것을 공공기관(KOICA)과 한국시민사회가 ODA 프로그 램을 추진하는 데 활용하는 것이다.

마지막으로, 기업의 CSR 지수와 시민사회의 CSI 지표 그리고 $\mathrm{KOICA}$ 의 시민사회 협력프로 그램을 종합적으로 연계한 협력프로그램을 개발할 필요가 있다. 왜냐하면 현재 기업은 CSR을 통해 개발협력의 주체이자 후원자로서 활동하고 있기 때문이다. 이 프로그램이 개발된다면 
$\mathrm{OECD} \mathrm{DAC}$ 의 공여국들이 진행하고 있는 시민사회 지원프로그램 가운데서 매우 독창적인 프로 그램이 될 수 있을 것이다.

한국 $\mathrm{ODA}$ 를 선진국 수준으로 질적 개선을 하기 위해서는 효과적인 시민사회 개발협력 프로

그램을 개발하여야 한다. CIVICUS의 시민사회 지표는 향후 정부(특히 KOICA)가 추진하려는 $\mathrm{ODA}$ 선진화 방안의 기초자료 및 개도국 시민사회와 $\mathrm{ODA}$ 협력사업에 필요한 안내 지표로 활 용할 수 있을 것이다. 


\section{참고문헌}

\section{1. 국내문헌}

국제개발협력위원회. 2010. 『국제개발협력 선진화 방안』, 서울: 국제개발협력위원회.

권혁태 외. 2003.『아시아의 시민사회-개념과 역사』, 서울: 아르케.

경희대NGO대학원 NGO평가팀. 2010. NGO지원사업종합평가, 『국제개발협력』, 4호, pp.195-220

김성규. 2012. “기업의 글로벌 사회적 책임과 개발협력”, 『국제개발협력』, 2호, pp.29-43.

김은미 외. 2010. “선진원조기관의 DAC 권고사항 및 평가지표 적용 현황과 $\mathrm{KOICA}$ 의 대응방향연구”, 한국국제협력단.

권율 외. 2009. ${ }^{\mathrm{O}} \mathrm{OECD} / \mathrm{DAC}$ 주요 규범과 $\mathrm{ODA}$ 정책 개선방향』, 서울: 대외경제정책연구원.

박재창. 2006.『지구시민사회와 한국NGO」, 서울: 오름.

서용석. 2011.『선진국ODA정책의 효과성 분석에 관한 연구』, 서울: 한국행정연구원

오삼교 외. 2011. 『중남미진출 한국기업의 사회적 공헌(CSR) 제고방안 연구』,

서울: 대외경제정책연구원.

이남주 외. 2005.『아시아의 시민사회(II)-현재와 전망』, 서울: 아르케.

이련주. 2010. “국제개발협력 선진화 방안”, 『국제개발협력』, 4호, pp.124-143.

이성훈. 2012. "국제개발협력과 시민사회(CSO)의 역할:부산총회 이후의 맥락에서", 『국개발협력』, 1호, pp.89-115.

주성수 편저. 2006. 『한국시민사회 지표』, 서울: 아르케

홍재환. 2011. 『ODA정책에서의 시민사회단체 협력 개선 방안 연구』, 서울: 한국행정연구원 한국국제협력단. 2011.『한국해외봉사단 20년 발자취』, 서울: KOICA 


\section{2. 국외문헌}

CIVICUIS. 2011. Brdging the gaps: Citizens, organizations and dissociation. Civil Society Index Summary report: 2008-2011.

CIVICUS, 2010. Assessing and Strengthening Civil Society Worldwide. An undated programme description of the CIVICUS Civil Society Index: Phase 2008 to 2010.

CIVICUS, 2007. CIVICUS Global Survey of the State of Civil Society. Vol.1 Country Profiles. USA: Kumarian Press.

Salamon, L. and Anheier, H. 1997. "Toward a Common Definition" in Salamon and Anheier eds. Defining the Nonprofit Sector. Manchester University Press. 